\title{
To study the association between initial fetal crown-rump length and subsequent abortion in a viable first trimester pregnancy
}

\author{
Rujuta Balsane*, Jyotsna Vyas, Lata Rajoria, Pratibha Agarwal, Surbhi Gupta
}

Department of Obstetrics and Gynecology, SMS Medical College, Jaipur, Rajasthan, India

Received: 26 May 2016

Accepted: 31 May 2016

\section{*Correspondence:}

Dr. Rujuta Balsane,

E-mail: rujutabalsane@gmail.com

Copyright: (c) the author(s), publisher and licensee Medip Academy. This is an open-access article distributed under the terms of the Creative Commons Attribution Non-Commercial License, which permits unrestricted non-commercial use, distribution, and reproduction in any medium, provided the original work is properly cited.

\begin{abstract}
Background: Ultrasonography is one of the most important and useful diagnostic tool in the field of modern medicine. In the $1^{\text {st }}$ trimester fetal crown rump length correlates closely with gestational age and is often used as the gold standard for dates. It provides the most accurate estimate of gestational age and crown rump length at 6-10 weeks predicts the due date with an accuracy of \pm 3 days. The objective of the study is to study the association between initial fetal crown-rump length (CRL) and subsequent abortion in a viable first trimester pregnancy.

Methods: Hospital based analytic type of observational study was conducted in a tertiary care maternity hospital. The recruited participants were young pregnant women at 6-10 weeks of viable gestation. Transvaginal ultrasonography was performed to determine pregnancy viability and measure the embryonic CRL.75 first trimester pregnancy cases with normal initial crown-rump-length and 75 first trimester pregnancy cases with deficit initial crown-rump-length were taken. The deviation of observed and expected CRL was calculated and expressed in standard deviations (SD) as $\mathrm{Z}$ - score. The primary outcome measure was the percentage of pregnancies with antecedent growth delay that aborted by the end of the first trimester.

Results: In 150 women who met with the inclusion criteria, the pregnancy remained viable in $97(64.66 \%)$ and 53 $(35.34 \%)$ suffered abortion. At the first transvaginal ultrasound, the mean Z- score for CRL was significantly lower in pregnancies that subsequently aborted compared to pregnancies that remained viable $(-0.613$ vs 0.335 , respectively, $\mathrm{P}$ $<0.001)$. Among 75 cases of normal CRL $65(86.67 \%)$ remained viable and $10(13.33 \%)$ aborted and in deficit CRL $32(42.67 \%)$ cases remained viable and $43(57.33 \%)$ aborted. Out of 53 pregnancies which aborted $43(81.13 \%)$ had deficit CRL. Significant difference was present ( $\mathrm{P}<0.001$, significant).

Conclusions: We infer that a deficit in initial fetal CRL in a viable first trimester pregnancy has a significant positive association with subsequent abortion. With increasing deviation of observed CRL from the expected CRL the risk of subsequent abortion increases.
\end{abstract}

Keywords: Crown-rump-length, Transvaginal ultrasonography, Abortion

\section{INTRODUCTION}

The $1^{\text {st }}$ detection of embryonic heart motion by ultrasound does not ensure ongoing pregnancy viability, even in the absence of symptoms. Spontaneous abortion occur even after embryonic heart motion has been detected in $2-16 \%$ cases. $^{1-4}$ Ultrasonography is one of the most important and useful diagnostic tool in the field of modern medicine. In the $1^{\text {st }}$ trimester fetal crown rump length correlates closely with gestational age and is often used as the gold standard for dates. It provides the most accurate estimate of gestational age and crown rump length at 6-10 weeks predicts the due date with an accuracy of \pm 3 days. The introduction of the higher frequency transvaginal probe, with its higher resolution of images, opens new possibilities to study early gestation. Ultrasound findings that have been seen with subsequent abortion include a slow fetal heart rate, a 
small gestational sac diameter, larger than expected yolk sac diameter, deformed or absent yolk sac and a deficit in crown rump length. Thus measurement of fetal crown rump length is frequently used to determine the gestational age of a normal pregnancy during the $1^{\text {st }}$ trimester with great accuracy.

One possible link between a small crown rump length and subsequent abortion is that chromosomal defects not only have a high intrauterine lethality rate but can also be associated with fetal growth restriction in the first trimester of pregnancy.

Thus we want to assess whether spontaneously conceived viable singleton pregnancies which subsequently end in abortion have a different pattern from those that remain viable and can this deficit in crown rump length be used to predict the occurrence of subsequent abortion.

The aims of the study are to examine whether viable early pregnancy that subsequently abort exhibit deficit crown - rump length and to assess and compare the proportions of abortions in deficit crown rump length versus normal crown rump length.

\section{METHODS}

This is hospital based analytic type of observational study in department of obstetrics and gynaecology, SMS Medical College, Jaipur, India since June 2014 to December 2015.75 first trimester pregnancy cases with normal initial crown-rump-length and 75 first trimester pregnancy cases with deficit initial crown-rump-length were taken with informed and written consent.

All women with viable singleton intrauterine pregnancies at 6-10 completed weeks of gestation calculated from LMP, with certain or reliable menstrual dates and regular menstrual cycle 26 to 30 days with spontaneous conception and no hormonal contraception use or pregnancy or breast feeding in last 3 months preceding the LMP were included in study.

Women with vaginal bleeding or pain abdomen, with multifetal, extrauterine, non-viable or molar pregnancies, with uterine anomalies, with conception after assisted reproductive techniques (ART), with significant past medical illness were excluded.

A detailed history comprising age, menstrual cycle, duration of amenorrhea, gravidity, parity, weight, height, previous history of abortion and medical illness, socioeconomic status, smoking, any drug addiction was elicited. General physical and systemic examination was done. Vaginal examination was done to assess gestational age, unhealthy discharge, condition of OS and to rule out any pelvic pathology. Selected cases underwent transvaginal ultrasonography by the same senior sonologist posted in Radiology department at SMS Hospital to avoid inter-observer variance as far as possible to determine pregnancy, location, number of embryos, viability, gestational age and embryonic crown rump length.

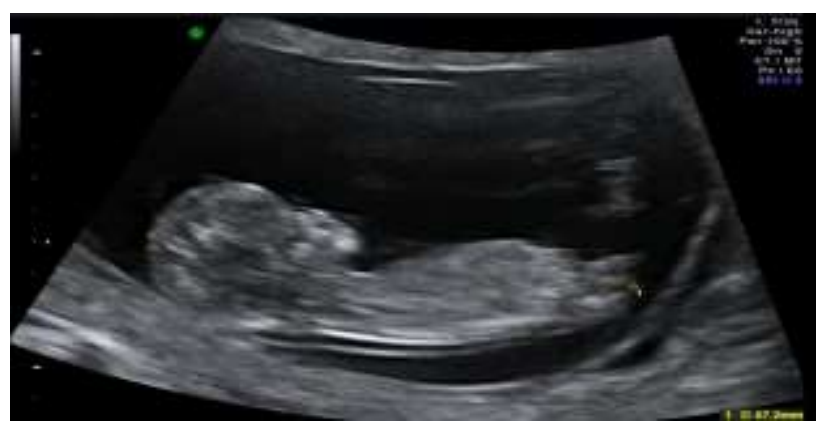

Figure 1: Features of correct CRL measurement.

\section{Correct method of crown rump length Measurement}

- Mid-sagittal section: The profile, spine and rump are visible

- Horizontal position: Almost 90o to the ultrasound beam

- Neutral position: There is fluid visible between the chin and the chest of the fetus

- Good magnification: The fetus fills almost the entire screen

- Correct calliper position: The intersection of the callipers should be placed on the outer borders of the skin over the head and rump

\section{Statistical analysis}

The deviation between the observed and expected crownrump length (crown rump length) for gestation were calculated and expressed in SD as a ' $\mathrm{Z}$ ' score.

The primary outcome was either continuing viability of the pregnancy beyond the first trimester, as determined by viability at the routine 11-14 week ultrasound assessment or abortion.

\section{RESULTS}

This study was done in Zenana Hospital, SMS Medical College, Jaipur, India between June 2014 to December 2015 in department of obstetrics and gynaecology. This study involved transvaginal sonography of all the 150 participants to assess initial crown rump length and to find out its prognostic value in $1^{\text {st }}$ trimester.

Among 75 cases of normal CRL 65 (86.67\%) remained viable and $10(13.33 \%)$ aborted and in deficit CRL 32 $(42.67 \%)$ cases remained viable and $43(57.33 \%)$ aborted. Out of 53 pregnancies which aborted $43(81.13 \%)$ had deficit CRL (Table 1). Significant difference was present (P<0.001, Significance). 
Table 1: Distribution of cases according to initial CRL and subsequent pregnancy outcome.

\begin{tabular}{|l|llll|}
\hline \multirow{2}{*}{ Pregnancy outcome } & \multicolumn{2}{c|}{ Normal CRL } & \multicolumn{2}{c|}{ Deficit CRL } \\
\cline { 2 - 5 } & No. & \% & No. & \% \\
\hline Remained viable & 65 & 86.67 & 32 & 42.67 \\
\hline Aborted & 10 & 13.33 & 43 & 57.33 \\
\hline Total & 75 & 100.00 & 75 & 100.00 \\
\hline
\end{tabular}

The mean expected CRL in pregnancies that remained viable was 14.607, while in those that subsequently aborted, the mean expected CRL was 15.595 (Table 2). There was no statistically significant difference between the groups in mean expected CRL $(\mathrm{p}=0.302)$.

Table 2: Mean expected CRL (in mm) and subsequent pregnancy outcome.

\begin{tabular}{|ll|}
\hline Outcome & Mean expected CRL \\
\hline Remained viable (97) & 14.607 \\
\hline Abortion (53) & 15.595 \\
\hline
\end{tabular}

The mean observed CRL in pregnancies that remained viable was 13.334, while in those that subsequently aborted, the mean expected CRL was 10.759 (Table 3). There was statistically significant difference between the groups in mean observed CRL $(\mathrm{p}=0.005)$.

Table 3: Mean observed CRL (in mm) and subsequent pregnancy outcome.

\begin{tabular}{|ll|}
\hline Outcome & Mean observed CRL \\
\hline Remained viable (97) & 13.334 \\
\hline Abortion (53) & 10.759 \\
\hline
\end{tabular}

The mean Z-score for CRL in pregnancies that remained viable was 0.335 , while in those that subsequently aborted, the mean $\mathrm{Z}$ score for CRL was -0.613 (Table 4). Significant difference was present as p-value $<0.001$.

Table 4: Mean Z-score and subsequent pregnancy outcome.

\begin{tabular}{|ll|}
\hline Outcome & Mean Z-score \\
\hline Remained viable (97) & 0.335 \\
\hline Abortion (53) & -0.613 \\
\hline
\end{tabular}

The risk of abortion was $30.32 \%$ in those with CRL within 1 SDs, the risk was $45 \%, 85.70 \%$ and $100 \%$ for those with a CRL between -1 and -2 SDs, -2 and -3 SDs and more than -3 SDs, respectively.

This showed that the risk of subsequent abortion increases with increasing deviation from the expected CRL.

\section{DISCUSSION}

Every pregnancy is special and different. An accurate model for the prediction of subsequent abortion occurring in early live pregnancies has not yet been established. Early delay in fetal growth has been documented in pregnancies that subsequently abort. The diagnosis of growth delay is based on fetal size, less than expected, and thus it is crucial to have accurate information of the fetus, gestational age and the normal size range for the fetus of that age. Measurement of fetal crown-rump length is used to determine the gestational age of a normal pregnancy during the $1^{\text {st }}$ trimester with great accuracy. ${ }^{5}$ The smaller than expected crown-rump length has also been associated with subsequent pregnancy loss. In the present study about $86 \%$ of foetuses with normal CRL and only $32 \%$ with deficit CRL remained viable and this is comparable to the observations made by Abuelghar WM et al and Mukri $F$ et al. ${ }^{6,7}$ Similarly the mean observed CRL in pregnancies that remained viable was 13.33 while in those that subsequently aborted the mean expected CRL was 10.76. This was statistically significant and was again comparable to the observation made by Abuelgher WM et al. ${ }^{6}$ The mean Z-score for CRL in pregnancies that remained viable was 0.335 while in those that subsequently aborted, the mean $\mathrm{Z}$ score for CRL was -0.613 and this was comparable to the observations made by Mukri $\mathrm{F}$ et al and Abuelghar WM et al whose $\mathrm{z}$ score was -2.42 and -2.9 respectively. ${ }^{6,7} \mathrm{It}$ has been known that the risk of subsequent abortion increases with increasing deviation from the expected CRL. The study showed that the risk of abortion was $30 \%$ in those with CRL within $1 \mathrm{SD}$, the risk was $45 \%$, $85.6 \%$ and $100 \%$ for those with a CRL between -1 and -2 SDs, -2 and -3 SDs and less than -3 SDs, respectively and this too was comparable to the study conducted by Mukri F et al and Dickey RP et al.

\section{CONCLUSION}

From this prospective study, we infer that a deficit in initial fetal CRL in a viable first trimester pregnancy has a significant positive association with subsequent abortion. With increasing deviation of observed CRL from the expected CRL the risk of subsequent abortion increases. This ability to make an accurate risk prediction is important in counselling prospective parents and also rationalises the use of additional scans.

In the future by this concept we hope to be able to triage the women after their first visit, reassure those women at low risk of abortion and arrange close follow-up for those women who are at high risk.

\author{
Funding: No funding sources \\ Conflict of interest: None declared \\ Ethical approval: The study was approved by the \\ Institutional Ethics Committee
}




\section{REFERENCES}

1. Frates MC, Benson CB, Doubilet PM. Pregnancy outcome after a first trimester sonogram demonstrating fetal cardiac activity. J Ultrasound Med. 1993;12:383-6.

2. Cashner A, Christopher CR, Dysert GA. Spontaneous fetal loss after demonstration of a live fetus in the first trimester. Obstet Gynecol, 1987;70:827-31.

3. Wilson RD, Kendrick V, Wittmann BK, McGillivray B. Spontaneous miscarriage and pregnancy outcome after normal first trimester ultrasound examination. Obstet Gynecol. 1986;67:352-5.

4. Hill LM, Guzick D, Fries J, Hixson J. Fetal loss rate after ultrasonically documented cardiac activity between 6 and 14 weeks' menstrual age. J Clin Ultrasound. 1991;19:221-3.
5. Bottomley C, Bourne T. Dating and growth in the first trimester. Best Pract Res Clin Obstet Gynaecol. 2009;23:439-52.

6. Abuelghar WM, Fathi HM, Ellaithy MI and Anwar MA. Can a smaller than expected crown-rump length reliably predicts the occurrence of subsequent miscarriage in a viable first trimester pregnancy? J Obstet Gynaecol Res. 2013;39(10):1449-55.

7. Mukri F, Bourne T, Bottomley C, Schoeb C, Kirk E, Papageorghiou AT. Evidence of early first-trimester growth restriction in pregnancies that subsequently end in miscarriage. BJOG;2008;115(10):1273-8.

8. Dickey RP, Gasser RF, Olar TT, Curole DN, Taylor SN, Matulich ME, et al. The relationship of initial embryo crown-rump length to pregnancy outcome and abortus karyotypes based on new growth curves for the 2-31 mm embryo. Hum Reprod. 1994;9:36673.

Cite this article as: Balsane R, Vyas J, Rajoria L, Agarwal P, Gupta S. To study the association between initial fetal crown-rump length and subsequent abortion in a viable first trimester pregnancy. Int J Reprod Contracept Obstet Gynecol 2016;5:1744-7. 